CASE REPORT

\title{
Water and land based rehabilitation for Achilles tendinopathy in an elite female runner
}

\author{
A G Beneka, P C Malliou, G Benekas
}

Br J Sports Med 2003;37:535-537

A 17 year old female athlete presented with Achilles tendinopathy. A protocol of water and land based rehabilitation was designed to achieve non-weight bearing and pain free activity, so that she could rapidly return to her event (400 m hurdles). After three weeks, she returned to regular training, and after a further three weeks she successfully competed in a $400 \mathrm{~m}$ hurdle event. She has been able to compete at national level symptom free for the last 18 months.

The Achilles tendon is the largest and strongest tendon in the human body and experiences high loads in all sporting activities. It has been shown to have a high capacity to withstand tensional forces. ${ }^{1}$ Chronic painful conditions located in the Achilles tendon are relatively common, especially in runners. ${ }^{2}$ The cause of such conditions is not known, but they are often associated with repetitive loading and overuse. ${ }^{3}$ Achilles tendinopathy is difficult to treat. ${ }^{1}$ Most recommend a conservative regimen as the initial strategy. ${ }^{4-6}$ Non-surgical treatments include a combination of rest, antiinflammatory drugs, correction of malalignments, and stretching and strengthening exercises.

There is sparse scientific evidence that these treatments are successful, and surgical treatment is required in about $25 \%$ of patients. ${ }^{1}$ In a recent prospective study, treatment with heavy load, eccentric calf muscle training showed very promising results and may reduce the need for surgical treatment of tendinopathy located in the midportion of the Achilles tendon. ${ }^{1}$ The short term results of surgery are often very good, but in the few studies with long term follow up there are signs of deterioration with time. ${ }^{17}$ In addition, over the last two decades there has been a considerable increase in the incidence of Achilles tendon rupture. $^{8}$

Many athletic trainers propose an active land based rehabilitation training programme for Achilles tendinopathy, which includes strength and stretching exercises and balance exercises on unstable boards. However, many physiotherapists and aquatic exercise specialists have been using water to treat conditions of the lower extremity for many years. ${ }^{9}$ They maintain that water is the ideal environment for the rehabilitation of injuries for which weight bearing needs to be limited. Range of motion (ROM), strength, and functional activities performed in deep water are used to prepare the limb for weight bearing. The combination of buoyancy induced skeletal unloading and muscular relaxation can enhance ROM and flexibility. Land based tasks should be initiated before the water programme is finished to facilitate a smooth transition from pool to land. ${ }^{9}$ Over the last two decades, many athletes have routinely exercised in the pool when recovering from injury.

This study focuses on a specific rehabilitation programme (combination of aquatic and land based exercises) prescribed for a young female runner with early stage Achilles tendinopathy.

\section{CASE REPORT}

A 17 year old female athlete presented with gradually increasing pain located in the Achilles tendon area of her left foot. The clinical diagnosis was Achilles tendinopathy. She was prescribed anti-inflammatory drugs to alleviate the mildly painful symptoms. The symptoms decreased and she was able to compete in the preliminary rounds of the $400 \mathrm{~m}$ hurdles and gained a place in the finals to take place six weeks later. The following day, the painful symptoms in the Achilles tendon increased rapidly and spread around the posterior ankle area, so that even walking was painful. More specifically, the point tender pain and swelling was over the Achilles tendon (the middle section proximal to the calcaneal insertion). The tendon was sore on rising in the morning and stiff when she started to run. In addition, crepitus was present. She could not stand on tip toe, to go up or down stairs. On examination, movement from the neutral position to dorsiflexion (supine) was painful. After a clinical examination, she was advised to stop training. The athletic training team (an orthopaedic surgeon, a physiotherapist, and an athletic trainer) designed an aquatic rehabilitation programme to achieve early non-weight bearing and pain free activity.

\section{REHABILITATION PROGRAMME}

The goals were gait normalisation, to increase pain free dorsiflexion from $0^{\circ}$ to $20^{\circ}$, proprioception ability, calf muscle strength, and strength throughout the lower extremity, and to maintain cardiovascular endurance (table 1).

To maintain her cardiovascular condition, the athlete followed a daily swimming programme. The ankle joint was taped for protection and to keep the heel in a neutral position.

The early phase (lst week) of rehabilitation consisted nearly exclusively of exercises in the pool. Passive stretching exercises in the pool to increase ROM of the ankle joint (dorsiflexion and plantar flexion) paralleled stretching exercises on the land. Mild static balance and isometric exercises (after the 5th session) were performed in the water. Gait normalisation activities, including walking at different stride lengths in different directions at various depths and different speeds in the pool, were performed. Single-leg balance and wobble board exercises in the water were included. Strengthening exercises in this phase were primarily open kinetic chain because of the pain and substitution that occurred with closed kinetic chain activities. Dynamic strength exercises for the other lower limb muscle groups were also performed with specific equipment in the pool.

The intermediate phase focused on increasing gait endurance. Mild dynamic exercises for the gastrocnemius and soleus muscles were initiated in the pool in gradually decreasing depths of water. Full passive ROM was achieved. During this week, the pain decreased considerably. Land based exercises progressed to full weight bearing activities as tolerated, with the focus on stress to the Achilles tendon. 
Table 1 Water and land based rehabilitation programme for young female athlete with Achilles tendinopathy

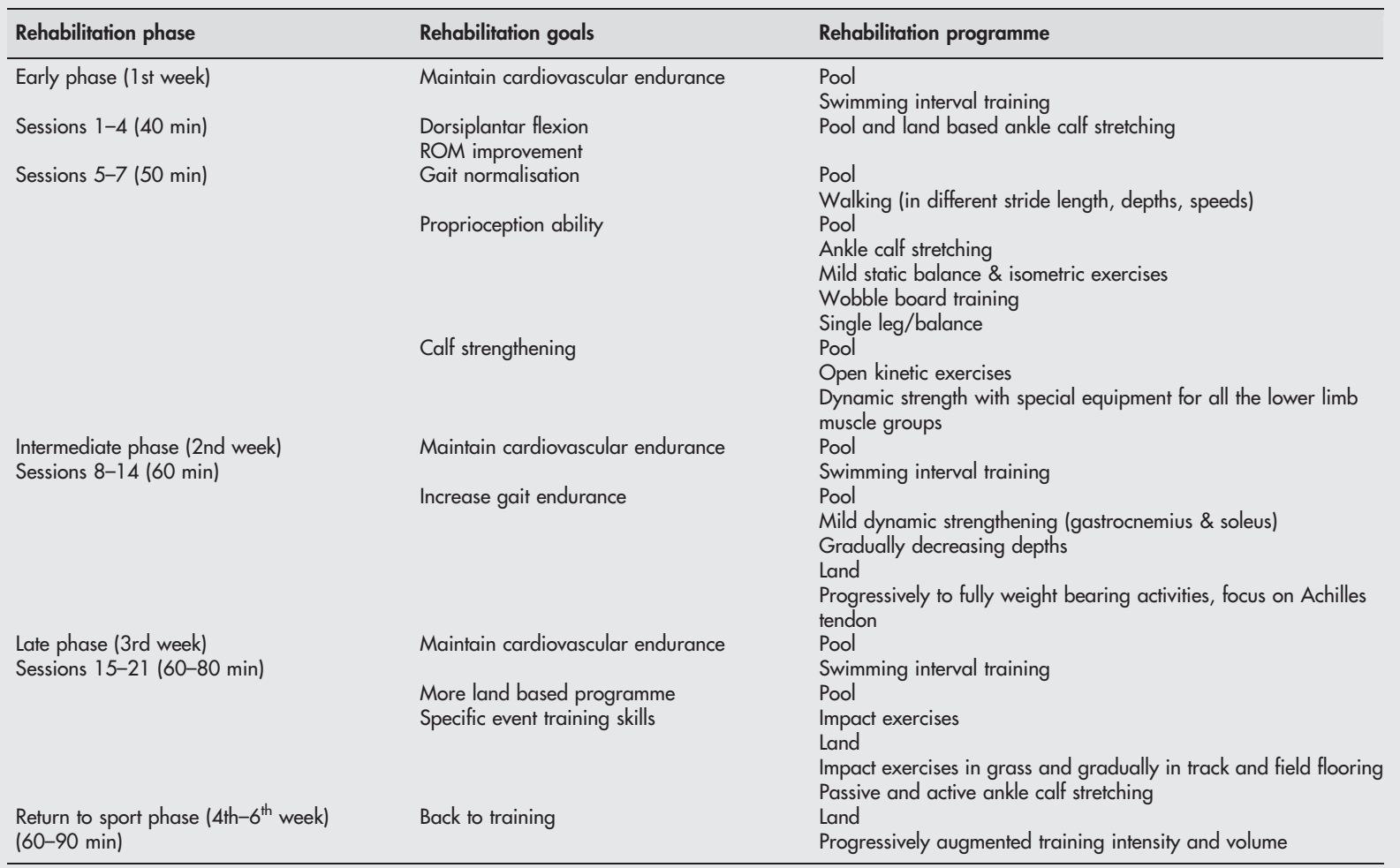

During the third week (the late rehabilitation phase), the time spent on land based exercises was increased and the amount of time spent in the pool was decreased. Impact exercises were initiated in the pool and progressed to land, first on grass and then to the traditional track and field surface. Passive and active stretching for the ankle and calf was performed. Over the next three weeks, the athlete started a progressive training programme in order to compete in the $400 \mathrm{~m}$ hurdle event. She won the race, achieving a new national record (61 seconds). She has had no further symptoms.

\section{DISCUSSION}

On initial presentation, the athlete was treated with antiinflammatory drugs. Although the symptoms decreased, the Achilles tendinopathy was not resolved. Kader et al maintain that Achilles tendinitis is a degenerative, not an inflammatory, condition. Although the present case was an early stage of Achilles tendinopathy, it also was not an inflammatory condition.

In our case study, a water based exercise programme was devised for the Achilles tendinopathy because it limits weight bearing using buoyancy. During the rehabilitation period, it is very important to protect the muscle-tendon unit from excessive torque or damaging vibrational forces. Premature loading of a damaged Achilles tendon can cause a number of adverse chemical, metabolic, and vascular changes. Rehabilitation progresses consistently when inflammation is kept to a minimum.' Therefore, the aquatic rehabilitation programme provided the early initiation of specific exercises (strengthening, stretching, and balance exercises of the ankle joint) to prevent atrophy, motion loss, and abnormal movement pattern development.

The cardiovascular swimming programme had two positive effects. Firstly, it maintained the athlete's cardiovascular condition, which is also an important aspect of early intervention. Secondly, as supported by many studies, ${ }^{11-13}$ it had positive effects on the healing tissues. These effects include increased blood flow and neurological stimulation, with minimisation of adjacent tissue weakness and adverse psychological effect. However, it is important that the athlete works within the constraints of his/her limitations. ${ }^{11-13}$

Passive and active (later) stretching exercises were necessary to maintain normal gait and facilitate normal anthropokinematics of the ankle and calf. Both types of stretching can be performed in or out of the water. ${ }^{1}{ }^{14}$

The wobble board exercises are good for stimulating proprioception. ${ }^{15}$ Water is an ideal environment for proprioception training because of its viscosity. Viscosity provides a slow motion, three dimensional resistive environment which facilitates proprioceptive feedback through functional movement patterns. This proprioceptive activity enables the athlete to incorporate safely advanced levels of dynamic stabilisation earlier in the rehabilitation schedule by decreasing both the demands of deceleration and joint excursion. ${ }^{914}$

During the early phase (first week), static and isometric exercises were performed. Dynamic activity was contraindicated because of the joint compression, vibration, and torsional forces that accompany these techniques, resulting in increased pain and inflammation. The athlete in this study was able to perform mild dynamic exercises (second week) earlier in the pool because of minimisation of some of these forces in this environment. Concentric and eccentric loading in single and then multiple planes (late phase) encouraged normal gastrocnemius and soleus function.

\section{CONCLUSION}

Aquatic rehabilitative exercises for Achilles tendinopathy provide an opportunity for the athlete to train in a gravity minimised environment while being immersed in a resistive medium. The unloading is critical as rehabilitation time can be minimised because safe and functional rehabilitation can 
be started immediately. This can minimise the injury and reduce recovery time.

The aquatic and land based programme reported here offered an effective rehabilitation protocol for the female athlete. However, a case study does not allow generalisation of the conclusions. Further investigation is needed to estimate the effectiveness of this early intervention in achieving rapid return to unlimited activity.

\section{Authors' affiliations}

A G Beneka, P C Malliou, G Benekas, Democritus University of Thrace, Komotini, Greece

Correspondence to: Assistant Professor Malliou, TEFAA, 7th Km Komotini Xanthi, Komotini 69100, Greece; malliou2002@yahoo.gr

Accepted 5 November 2002

\section{REFERENCES}

1 Alfredson H, Lorentzon R. Chronic Achilles tendinosis. Sports Med 2000;29: 135-46.

2 Maffulli N, Testa V, Capasso G, et al. Results of percutaneous longitudinal tenotomy for Achilles tendinopathy in middle- and long-distance runners. Am J Sports Med 1997:25:835-40.

3 Archambault JM, Wiley JP, Bray RC. Exercise loading of tendons and the development of overuse injuries. A review of current literature. Sports Med 1995;20:77-89.
4 Kvist M. Achilles tendon injuries in athletes. Sports Med 1994:18:173-201.

5 Sandmeier R, Renstrom RAFH. Diagnosis and treatment of chronic tendon disorders for the treatment of chronic Achilles tendinosis. Scand J Med Sci Sports 1997:7:96-106.

6 Alfredson $\mathrm{H}$, Pietila $\mathrm{T}$, Jonsson $\mathrm{P}$, et al. Heary-load eccentric calf muscles training for the treatment of chronic Achilles tendinosis. Am J Sports Med 1998;26:360-6.

7 Maffulli N, Binfield PM, Moore D, et al. Surgical decompression of chronic central core lesions of the Achilles tendon. Am J Sports Med 1999;27:747-52.

8 Maffulli N, Waterston SW, Squair J, et al. Changing the incidence of Achilles tendon rupture in Scotland: a 15 year study. Clin J Sport Med 1999;9:157-60

9 Ruoti R, Morris D, Cole A. Aquatic rehabilitation. Philadelphia: Lippincott Williams \& Wilkins, 1997:64-65, 212

10 Kader D, Saxena A, Movin T, et al. Achilles tendinopathy: some aspects of basic science and clinical management. Br J Sports Med 2002;36:239-49

11 Woo SI-Y, Buckwalkte JA, eds. Injury and repair of the musculoskeletal soft tissue. Park Ridge, IL: American Academy of Orthopedic Surgeons, 1988.

12 Frank CB, Hart DA. Cellular response to loading. In: Leadvetter WB, Buckwalkte JA, Gordon SL, eds. Sports induced inflammation: clinical and basic science concepts. Park Ridge, IL: American Academy of Orthopedic Surgeons, 1990

13 Kibler WB, Chandler RJ, Stracener ES. Musculoskeletal adaptations and injury due to overtraining. Exerc Sport Sci Rev 1992;20:99.

14 Kibler WB, Herring SA, Press JM, et al. Functional rehabilitation of sports and musculoskeletal injuries. Gaithersburg, MD: Aspen Publishers Inc, 1998:273-83.

15 Rozzi SL, Lephart SM, Sterner R, et al. Balance training for persons with functionally unstable ankles. J Orthop Sports Phys Ther 1999;29:478-86.

\section{Surfer wipe out by predator fish G M M J Kerkhoffs, J W op den Akker, E R Hammacher}

Needlefish injuries, commonly reported in the Indo-Pacific region, have not been previously reported along the European coastlines. This case report describes a penetrating injury to the heel of a professional surfer during competition off the Portuguese coast. Diagnostic as well as therapeutic recommendations are made.

$\mathrm{R}$ eports of hazardous marine animals have increased over the last two decades. ${ }^{12}$ Along the European seaboard, stingrays and catfish commonly cause penetrating injuries, but there are no reports of injury by needlefish. Human injuries by needlefish result from the ability of the fish to leap out of the water at high speed. Injury occurs by impalement of the needlefish beak. This produces a stab wound, often with the beak intact. Injuries by needlefish, especially among windsurfers, divers, and fisherman, have only been reported in New Caledonia, ${ }^{3}$ Papua-New Guinea, ${ }^{4}$ the Red Sea, ${ }^{5}$ and Hawaii. ${ }^{6}$ This case report describes a penetrating injury to the heel caused by a needlefish, which occurred during a professional surf contest in European waters. Management of the injury is discussed.

\section{CASE REPORT}

A 25 year old man presented to the emergency department of our hospital with persistent swelling and pain in his right heel. Two weeks before, while riding a wave in a professional competition off the coast in Portugal, he had suddenly felt a violent thump and pain in his right heel. The sharp pain and profuse bleeding caused him to be thrown off the wave and return to shore. On arrival in the Portuguese emergency ward, initial evaluation revealed a foreign body sticking out of the right heel. The doctor removed the protruding part of the foreign body and bandaged the wound. Thereafter the patient was discharged from further care.

Two days later, on return to the Netherlands, the heel was still warm, swollen, and painful. Consultation with the patient's general practitioner and sports medicine doctor resulted in prescription of rest and antibiotics (flucloxacillin $500 \mathrm{mg}$ four times a day) for seven days. After the antibiotic course had been completed, the swelling and pain persisted although there was no fever. Three days later the patient presented to the emergency department. Initial evaluation showed a painful, inflamed, fluctuating swelling at both the medial and lateral side of the right heel. The lateral wound produced a small amount of pus. Body temperature was $37.1^{\circ} \mathrm{C}$.

The presence of a foreign body was noted on a standard lateral radiograph of the heel. This was seen as opacity at the cranial border of the posterior part of the calcaneus. This opacity was shaped as two dense parallel lines (fig 1). With the clinical characteristics and our anamnestic experience, a fish wound was suspected. The fish was found to be a needlefish, a member of the Belonid family (fig 2). The patient was operated on the same day.

The patient underwent surgical exploration of the lateral and medial side of the right heel with removal of the fish remnants and careful debridement (fig 3). Antibiotics were not prescribed, because all the foreign body had been removed. The wound was left to heal by secondary intention. 


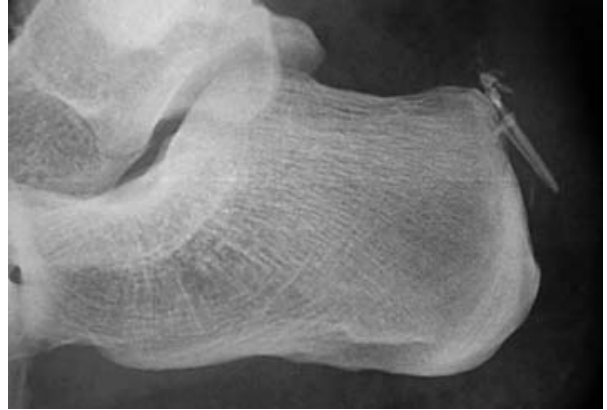

Figure 1 Lateral view radiograph of the right heel showing part of the beak at the cranial part of the posterior calcaneal border. The appearance of two semiparallel lines of opacity is typical of a needlefish beak.

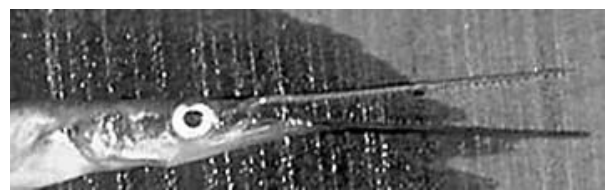

Figure 2 The Belonid needlefish.
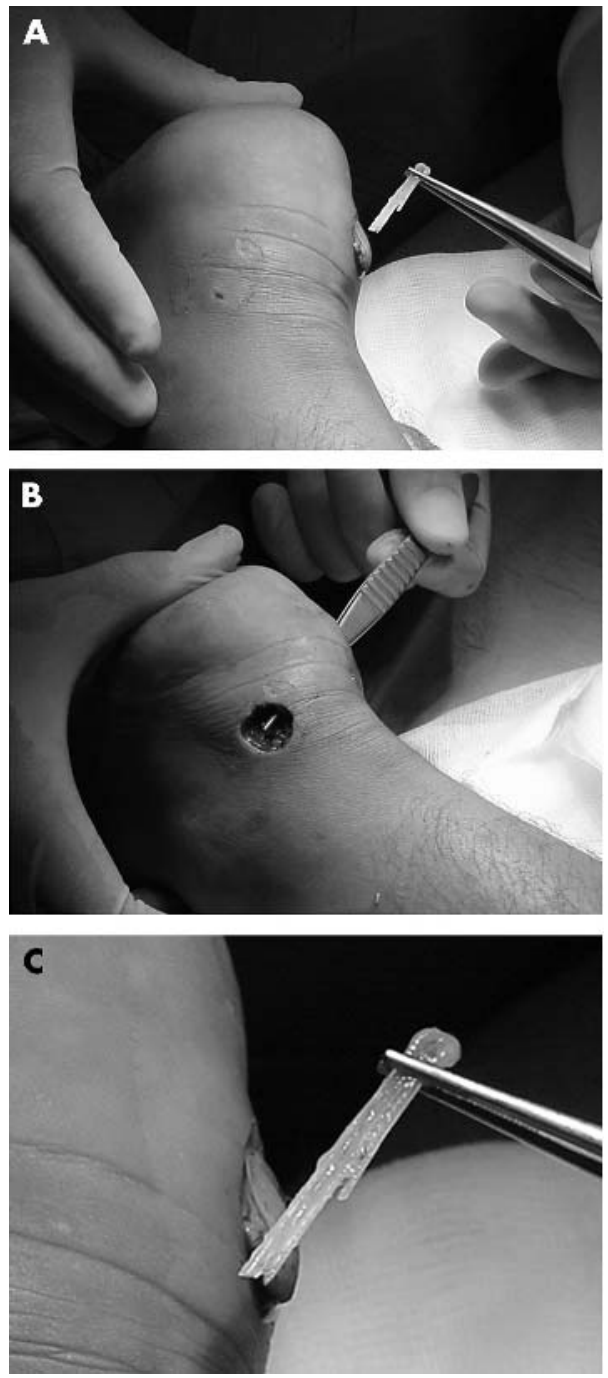

Figure 3 (A) Removal of part of the needlefish beak; (B) the heel after vigorous irrigation and debridement; $(C)$ the pieces of the beak removed.

\section{Take home message}

Penetrating injuries by needlefish require surgical intervention. The use of antibiotics is optional.

The wound was dressed with wet gauze and flushed twice daily. The patient was kept in hospital for two days, and immediate improvement was seen. There were no complications. Four weeks after the accident, the patient had resumed his professional activities.

\section{DISCUSSION}

Needlefish belong to the Beloniform order which is composed of two families, the Belonids and the Hemiramphids. These are found in (sub) tropical waters of all oceans. The fish are long and slender, ranging in length from $0.5 \mathrm{~m}$ to more than $1.5 \mathrm{~m}$. The long, narrow "beak" is comprised of jaws filled with sharp, little teeth. The colour, bluish green on top and silver on the bottom, is adapted for surface dwelling. Needlefish are surface carnivore predators.

Needlefish injury should not be confused with a stingray or catfish injury; all three fish produce penetrating injuries. However, stingray and catfish are bottom dwellers. Injury by a stingray typically occurs when it is stepped on or handled. Catfish injuries generally occur only while handling the fish. Both stingray and catfish cause injury with envenomation, which should be treated by immersion in hot water. Management of the wound is similar for all three.

A needlefish injury should be treated like a stab wound. The small diameter of the fish's snout allows it to penetrate between bony structures of the thorax, spinal canal, and skull. ${ }^{4}$ Abdominal, ocular, and articular injuries have also been described. ${ }^{3}$ After penetration of the skin, the beak can break into several fragments and inflict severe damage at a distance from the entry point. Standard radiographs are recommended to determine the presence of retained beak. The appearance of two semiparallel lines of opacity is typical of a needlefish beak. Radiographic and clinical evaluation lead to diagnosis and early surgical treatment.

There are no prospective studies providing evidence for optimal antibiotic selection for marine acquired infections or prophylaxis. Immunocompetent patients do not always require prophylaxis. A surgical debridement is the mainstay of treatment. Tetanus prophylaxis is required if not up to date. Wounds generally should be left to heal by secondary intention.

\section{Authors' affiliations}

G M M J Kerkhoffs, Academic Medical Center, Amsterdam, the Netherlands

G M M J Kerkhoffs, J W op den Akker, E R Hammacher, Department of General Surgery, Sint Antonius Hospital, Nieuwegein, the Netherlands

Correspondence to: Dr Kerkhoffs, Academic Medical Center, Orthopedic Surgery, Meibergdreef 9, Amsterdam 1100 DD, the Netherlands; ginokerkhoffs@hotmail.com

Accepted 5 November 2002

\section{REFERENCES}

1 Auerbach P. Hazardous marine animals. Emerg Med Clin North Am 1984;2:531-44.

2 Link KW, Counselman FL, Steele J, et al. A new hazard for windsurfers: needlefish impalement. J Emerg Med 1999;17:255-9. 
3 Labbe JL, Bordes JP, Fine X. An unusual surgical emergency: a knee joint wound caused by a needlefish. Arthroscopy 1995;11:503-5.

4 Barss PG. Penetrating wounds caused by needlefish in Oceania. Med J Aust 1985; 143:617-22.
5 Wolf $M$, Faibel $M$, Leventon $G$, et al. Penetrating cervical injury caused by a needlefish. Ann Otol Rhinol Laryngol 1995;104:248-50.

6 McCabe MJ, Hammon WM, Halstead BW, et al. A fatal brain injury caused by a needlefish. Neuroradiology 1978;15:137-9.

\section{Two cases of suprascapular neuropathy in a family}

\section{Ravindran}

Suprascapular entrapment neuropathy is well known in certain athletes, especially volleyball players. A brother and sister presented with right shoulder pain and wasting of the scapular muscles, particularly the infraspinatus. They had played volleyball for over six years and were forced to retire because of disability. Investigations showed involvement of the rhomboid muscles also, suggesting a probable extension of this syndrome to other nerves in the region such as the dorsal scapular nerve.

$\mathrm{S}$ uprascapular nerve entrapment with scapular and shoulder pain, associated with weakness and wasting of the spinati muscles, is well documented in sports people, especially volleyball players. ${ }^{1-6}$ Several mechanisms have been proposed to explain the symptoms, but excessive traction $^{7-9}$ or stretching of the nerve is the most plausible pathomechanism. When this condition develops with an identical clinical profile in two siblings, both volleyball players of some repute, then some anatomical peculiarity seems logical. A brother and sister presented with weakness and wasting of the right scapular muscles and the details are reported here.

\section{CASE REPORTS}

\section{Case 1}

A 35 year old right handed male volleyball player developed right shoulder and scapular pain after a strenuous match in 1986. He was forced to rest for several weeks but the pain remained unabated. Before the onset of pain, he played volleyball regularly for almost seven years, often representing the state.

Within 2-3 months, wasting of the scapular muscles was observed. He was briefly investigated by radiography and electrophysiology, when neurogenic changes were observed in the right infraspinatus muscle. A year later, he had surgical decompression of the right suprascapular nerve at two levels: the suprascapular notch and the spinoglenoid notch. The surgical notes did not indicate the presence of any nerve atrophy, tight ligaments, or ganglions. However, he continued to deteriorate with persistent pain and progressive wasting, even after decompression, while he continued to play volleyball. He had to retire from active sport around 1990. Since then the condition has stabilised and the pain lessened. However, the pain recurred when he became active again as a volleyball coach. He has no history of right shoulder injury or dislocation.

Physical examination showed an athletic man with no systemic disease or skeletal deformities. There was a surgical scar extending from the right scapula to the upper arm.

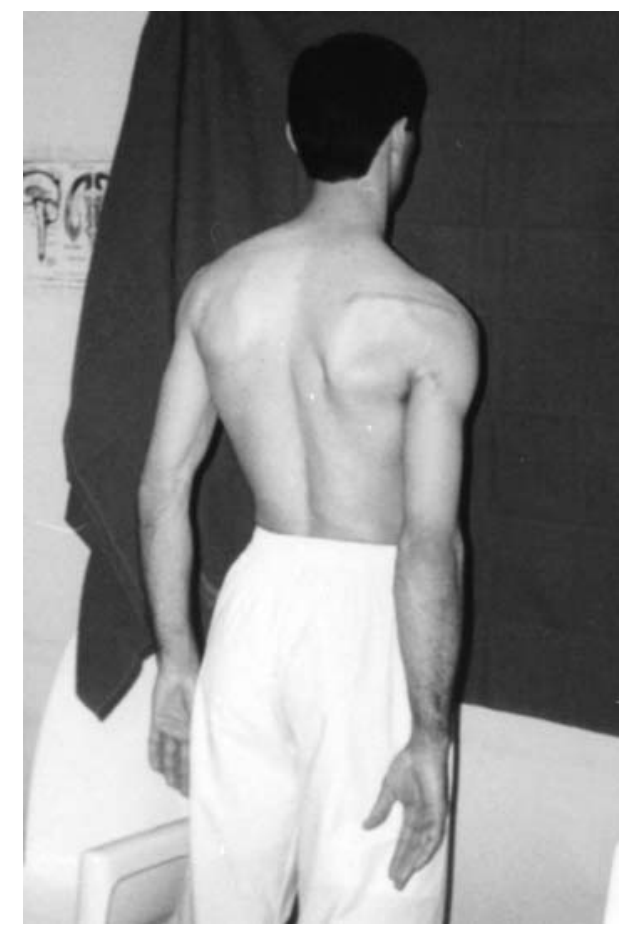

Figure 1 Wasting of the right infraspinatus muscle, with a surgical scar over the right scapula extending to the arm and mild winging of the scapula.

All cranial nerves were intact; no abnormality of the facial muscles, sternomastoids, or trapezii was found. He had considerable wasting of the right infraspinatus muscle with weakness of external rotation of the right arm (fig l). Right shoulder abduction was weak from initiation to $30^{\circ}$. He had mild winging of the right scapula but the power of the serratus anterior was near normal. There was no weakness or wasting of the right deltoid muscle. Other muscles were normal. No muscle fasciculations or myotonia was found.

Deep tendon reflexes were normal and symmetrical in both upper and lower limbs, and plantar responses were flexor bilaterally. All sensations were intact. The right shoulder showed a full range of passive movements. There was mild tenderness over the right scapular spine and acromioclavicular joint.

Routine haemogram, erythrocyte sedimentation rate, and blood chemistry were normal, including normal muscle enzymes. Collagen screening was negative. A radiograph of the right shoulder and cervical spine was normal. 
Electromyography of the right shoulder girdle muscles showed chronic neurogenic changes from the right infraspinati and supraspinati and rhomboid muscles. Normal response was found from the right deltoid, trapezius, and serratus anterior.

\section{Case 2}

The 27 year old sister of the patient in case I, a right handed volleyball player of about seven years duration, also developed shoulder and scapular pain on the right side about five years earlier, which worsened after vigorous games or matches. Wasting slowly became evident over the right scapula with some prominence of the bone. Because of persistent pain, she too had to retire from the game about two years earlier, and since then had no further progression.

On examination, there were no skeletal abnormalities, thyromegaly, or lymphadenopathy. Demonstrable abnormality was confined to the right scapular region. There was no weakness of the right trapezius or deltoid muscle. Weakness and wasting of the right infraspinatus with weakness of the supraspinatus and rhomboid muscles was demonstrable. There was mild winging of the right scapula at rest (fig 2), with no further increase on pushing or raising the arm (serratus anterior action). There were no myotonia or muscle fasiculations. She had normal and symmetric deep tendon reflexes and flexor plantar bilaterally. She had no sensory dysfunction or muscle tenderness. Passive movements of the right shoulder showed full range and no tenderness.

Blood chemistry including muscle enzymes, haemogram, erythrocyte sedimentation rate, and thyroid function were normal. Collagen screening was negative.

Radiographic and magnetic resonance imaging of the right shoulder, scapula, and cervical spine were normal.

Electromyographic investigation showed chronic neurogenic changes from the right supraspinati and infraspinati and rhomboid muscles. Trapezius, deltoid, and serratus anterior were normal.

She refused further investigations and surgical exploration.

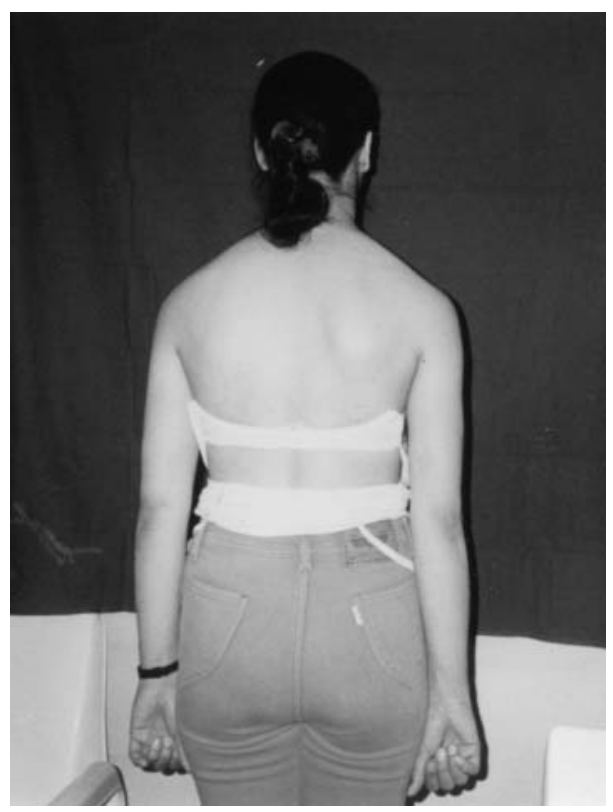

Figure 2 Wasting of right infraspinatus muscle with mild winging of right scapula.

\section{DISCUSSION}

Suprascapular nerve palsy due to entrapment is common in several sports activities, particularly volleyball..$^{1-6} 8{ }^{10}{ }^{11}$. Most of the reported cases are in professional volleyball players, and, in some, even asymptomatic atrophy of the infraspinatus muscle has been documented.'

The suprascapular nerve is a motor sensory peripheral nerve (C5) arising as a solitary branch from the superior trunk of the brachial plexus in the posterior triangle of the neck. ${ }^{8}$ It passes through the suprascapular foramen beneath the transverse scapular ligament, supplies the supraspinatus muscle, and sends sensory fibres to the acromioclavicular joint and subacromial bursa. Then it descends through the spinoglenoid notch to supply the infraspinatus muscle.

A common proximal site of entrapment of the nerve is at the suprascapular foramen, and hypertrophy or calcification of the transverse scapular ligament and other congenital malformations are among the probable causes. ${ }^{78}$ Distally, the nerve may become compressed at the fibro-osseous tunnel formed by the spine of the scapula and the spinoglenoid ligament. ${ }^{8}$ Suprascapular nerve entrapment with isolated paralysis of the infraspinatus muscle is uncommon, but has been reported in volleyball players. ${ }^{4}{ }^{6}$ A larger than normal range of mobility of the shoulder joint with greater traction injury during the game has been postulated as the probable cause. ${ }^{10}$

Shoulder pain is a common symptom in patients with suprascapular nerve entrapment and is characterised as a dull ache, exacerbated by overhead activities. ${ }^{8}$ The pain is articular in origin based on the sensory supply of the acromioclavicular joint and surrounding structures by the suprascapular nerve.

The interesting aspect of the cases reported here is the almost identical symptoms in two siblings, brother and sister, both volleyball players of repute. Both played in state teams for six or seven years before they developed shoulder pain and then muscle wasting. Thus the pattern of their disorder suggested a common anatomical peculiarity for the entrapment rather than coincidence. (There were six other siblings, three brothers and three sisters, who were not athletic and did not have this condition.)

There was clear evidence of maximal involvement of the right infraspinatus muscle in both, but the supraspinatus muscle was also involved clinically and electrophysiologically. In addition, there was slight winging of the scapula with demonstrable weakness of the rhomboid muscles. Serratus anterior muscle weakness produces prominent scapular winging, especially on pushing forward, with difficulty in lifting the arm beyond $90^{\circ}$. Weakness of the rhomboids may also cause mild winging of the scapula without interference with arm abduction and elevation. ${ }^{12}$ The patients reported here had no difficulty or weakness in raising the arm fully at the right shoulder with no further increase in scapular winging during such movements. The possibility of weakness of the rhomboid muscles should also be considered in the differential diagnosis as that too may produce winged scapula, without interfering with arm elevation. This problem was thus highlighted in both patients reported here. The dorsal scapular nerve (C5 nerve to the rhomboid muscles) also arises from the brachial plexus. Therefore there may be injury or entrapment of the C5 root somewhere in its course in these patients. However, this seemed unlikely, with the deltoid and other C5 root muscles being completely spared. Hence, the possibility of entrapment not only of the suprascapular nerve but also of the nerve to the rhomboids, with the suprascapular nerve dominating the clinical picture, arises. No previous report has shown involvement of the rhomboid muscles. Another possibility is an aberrant supply of the rhomboid muscles by the suprascapular nerve, but this 


\section{Take home message}

Suprascapular entrapment neuropathy is well documented in volleyball players. Here, a brother and sister, both volleyball players of repute, developed identical conditions of entrapment, suggesting selective vulnerability or anatomical variation as a possible explanation.

has not previously been reported and could not be confirmed in my patients.

Thus, the cases presented here open up a new dimension to this well documented syndrome, with a familial tendency probably indicating structural vulnerability or anatomical variance, and more extensive lesion, even outside the region of the suprascapular nerve, from similar causes related to the sport.

\section{Authors' affiliations}

M Ravindran, Ibn Sina Hospital, PO Box 25427 13115, Safat, Kuwait; ibnsinaq8@hotmail.com

\section{REFERENCES}

1 Ferretti A, Cerullo G, Russo G. Suprascapular neuropathy in volleyball players. J Bone Joint Surg [Am] 1987;69:260-3.

2 Feretti A, Decarli A, Fontana M. Injury of the suprascapular nerve at spinoglenoid notch. The natural history of infraspinatus atrophy in volleyball players. Am J Sports Med 1998;26:759-63.

3 Holzgrafe M, Kukowski B, Eggert S. Prevalence of latent and manifest suprascapular neuropathy in high performance volleyball players. Br J Sports Med 1994:28:177-9.

4 Montagna P, Colonna S. Suprascapular neuropathy restricted to the infraspinatus muscle in volleyball players. Acta Neurol Scand 1993;87:248-50.

5 Sandow MJ, llac J. Suprascapular nerve rotator cuff compression syndrome in volleyball players. J Shoulder Elbow Surg 1998;7:516-21.

6 Wang DH, Koehler SH. Isolated infraspinatus atrophy in a collegiate volleyball player. Clin J Sport Med 1996;6:255-8.

7 Rengachary SS, Neff JP, Singer PA, et al. Suprascapular entrapment neuropathy: a clinical, anatomical and comparative study. Part I. Clinical study. Neurosurgery 1979;5:441-6.

8 Cummins CA, Messer TM, Nuber GW. Suprascapular nerve entrapment. $J$ Bone Joint Surg $(A m)$ 2000;82:415-24.

9 Collaghan JD, Scully TB, Shapiro SA, et al. Supracapular nerve entrapment. A series of 27 cases. J Neurosurg 1991;74:893-6.

10 Witrouw E, Cools A, Lysens R, et al. Suprascapular neuropathy in volleyball players. Br J Sports Med 2000;34:174-80.

11 Cummins CA, Bowen M, Anderson K, et al. Suprascapular nerve entrapment at the spinoglenoid notch in a professional base ball pitcher. Am J Sports Med 1999.27:810-12.

12 Kahle W, Leonhardt H, Platzer W. Atlas/text of human anatomy: locomotor system, 4th ed. New York: Thieme Medical Publishers, 1992:142.

\title{
Saphenous nerve injury after fasciotomy for compartment syndrome
}

\author{
D Pyne, A S M Jawad, N Padhiar
}

Br J Sports Med 2003;37:541-542

A case is reported of chronic exertional compartment syndrome treated by fasciotomy. The decompression procedure was complicated by injury to the saphenous nerve. The importance of accurate placement of the posteromedial incision line to avoid saphenous nerve injury is highlighted.

Compartment syndrome refers to muscle ischaemia following small vessel occlusion resulting from an increase in local tissue pressure within a closed fascial compartment (fig 1). The condition may be acute (usually secondary to trauma) or less commonly chronic, secondary to exertion. The definitive treatment is surgical decompression of the compartment by fasciotomy. We describe a case of chronic exertional compartment syndrome (CECS) treated by fasciotomy. The decompression procedure was complicated by injury to the saphenous nerve.

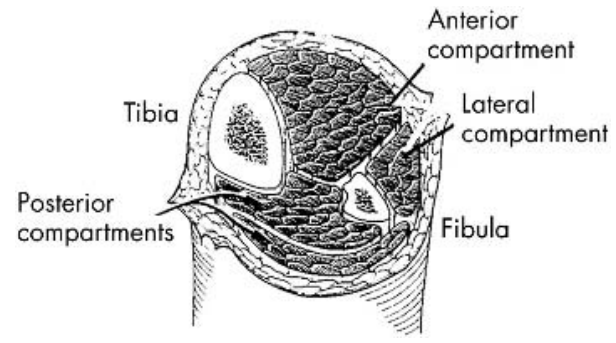

Figure 1 Compartments of lower limb.

\section{CASE HISTORY}

A 24 year old kickboxer, with no previous medical history, presented with pain in both shins and posteromedial aspect of his calf muscles, after an increase in his training level. The pain would slowly resolve over hours on cessation of training but would recur when training was restarted. Physical examination failed to show any abnormal clinical signs. Radiographs of tibiae and fibulae were normal. An isotope bone scan excluded any stress fractures. Intracompartmental pressure measurements were made at rest and during a variety of sprinting exercises. The resting measurements were $25 \mathrm{~mm} \mathrm{Hg}$ in both deep posterior compartments rising to $35 \mathrm{~mm} \mathrm{Hg}$ in the left posterior compartment during exercise. The resting pressures were $35 \mathrm{~mm} \mathrm{Hg}$ in both anterior compartments rising to $45 \mathrm{~mm} \mathrm{Hg}$ in both compartments during exercise. This confirmed the diagnosis of CECS in both anterior and left deep compartments. ${ }^{1}$ The patient subsequently underwent bilateral compartmental decompression. His original symptoms resolved, but two weeks after surgery he developed a diffuse burning pain extending from below the knee at the end of the anterior incision, down the medial shin to the region of the arch of the left foot. The pain was persistent. The ankle and knee jerks were both present, and there was no evidence of any weakness. A repeat of the intracompartmental pressure measurements and an isotope bone scan showed no abnormality. Nerve conduction studies found no activity in the left saphenous nerve, indicating that the nerve had been severed. Tinel's sign could not be elicited. The stump of the nerve was identified by nerve conduction studies, but identification was also aided by the presence of a small neuroma which was hypersensitive to the touch. This 


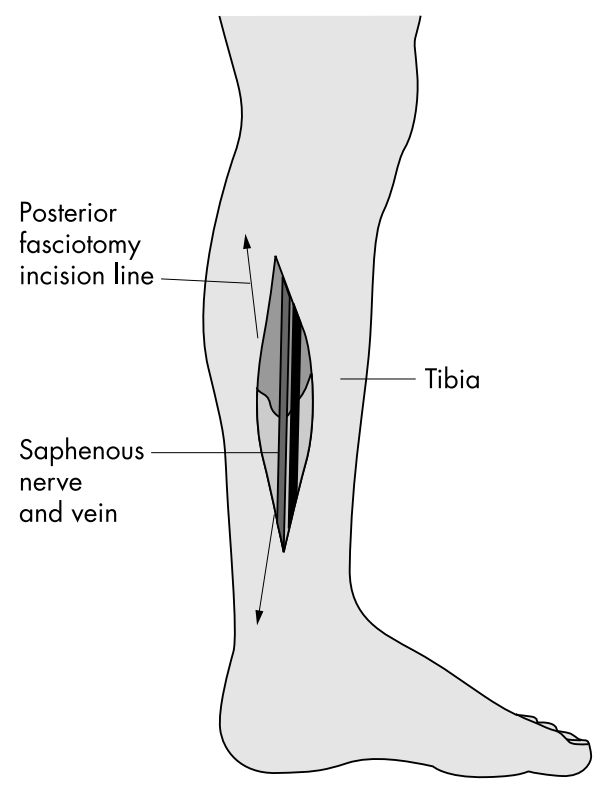

Figure 2 Diagram showing the relation of the fasciotomy line to the saphenous nerve.

stump was blocked with bupivacaine with immediate symptomatic relief.

\section{DISCUSSION}

The saphenous nerve is the cutaneous branch of the femoral nerve. Dysfunction of the saphenous nerve causes loss of sensation extending from below the knee down the medial shin to the region of the arch of the foot. Occasionally the infrapatellar branch of the saphenous nerve is damaged as the result of mild trauma or knee operations, producing the syndrome of gonyalgia paraesthetica, which includes sensory loss in a patch of several centimetres diameter below the knee, with intermittent lancinating pains.

Fasciotomy is generally a safe and effective treatment for CECS, with success rates greater than $90 \%{ }^{2}$ Complications include wound infection, haematoma, ulceration, deep venous thrombosis, and muscle herniation. ${ }^{2}$ Injury to the superficial peroneal nerve is recognised, with fasciotomy for anterior and lateral compartments where the incision line lies halfway between the fibula shaft and the tibial crest, directly over the superficial peroneal nerve.
For superficial and deep compartment decompression, a posteromedial incision $5-6 \mathrm{~cm}$ long is used $2 \mathrm{~cm}$ posterior to the tibial margin. An incision made anteriorly risks damage to the underlying saphenous nerve (fig 2).

The saphenous nerve is in particular danger during operations on varicose veins. ${ }^{3}$ Removal of the saphenous vein for use as an arterial graft poses the same risk. ${ }^{5}$ Saphenous nerve damage occurred in 3\% of 421 patients in one operative study. ${ }^{6}$ Cannulation of the saphenous vein at the ankle may injure the nerve and produce permanent painful paraesthesiae. ${ }^{7}$

Many patients with a saphenous neuropathy have relatively trivial numbness in the distribution of this nerve, but severe neuropathic pain can occur. There is often sensory loss and a tender neuroma may be present. The course of the nerve should be palpated carefully for areas of tenderness and a Tinel's sign.

To our knowledge this complication has not been previously reported after fasciotomy for compartment syndrome. This case report highlights the importance of accurate placement of the posteromedial incision line to avoid saphenous nerve injury, which should be added to the list of potential complications of decompression fasciotomy.

\section{Authors' affiliations}

D Pyne, A S M Jawad, N Padhiar, Department of Rheumatology, The Royal London Hospital (Mile End), Bancroft Road, London E1 4DG, UK

Correspondence to: Dr Pyne; dpyne@supanet.com

Accepted 5 November 2002

\section{REFERENCES}

1 Pecina MM, Krmpotic-Nemaniac J, Markiewitz AD. Saphenous nerve syndrome. In: Tunnel syndromes: peripheral nerve compression syndromes, 3rd ed. Boca Raton: CRC Press, 2001:229-31.

2 Detmer DE, Sherpe K, Sufit R, et al. Chronic compartment syndrome: diagnosis, management and outcomes. Am J Sports Med 1985;13:162-70.

3 Garnjobst W. Injuries to the saphenous nerve following operations for varicose veins. Surg Gynecol Obstet 1964;119:359-61.

4 Chauhan BM, Kim DJ, Wainapel SF. Saphenous neuropathy: following coronary artery bypass surgery. NY State J Med 1981;81:222-3.

5 Nair UR, Griffiths G, Lawson RA. Postoperative neuralgia in the leg after saphenous vein coronary artery bypass graft: a prospective study. Thorax 1988;43:41-3.

6 Lederman RJ, Brever AC, Hanson MR, et al. Peripheral nervous system complications of coronary bypass graft surgery. Ann Neurol 1982; 12:297-301.

7 Mozes M, Ouaknine G, Nathan H. Saphenous nerve entrapment simulating vascular disorder. Surgery 1975;77:299-303. 